\title{
Rock Breakage Using Expansive Cement
}

\author{
Amr El Dessouki, Hani Mitri \\ Department of Mining and Materials Engineering, McGill University, Montreal, Canada \\ E-mail: amr.eldessouki@mail.mcgill.ca \\ Received November 16, 2010; revised January 10, 2011; accepted January 27, 2011
}

\begin{abstract}
Expansive cements are powdery materials which produce expansive stresses during the moist curing process. These cements are classified as shrinkage-compensated or self-stressing cements. The shrinkage compensated is used in the construction industry and will not be investigated in this paper. Self-Stressing cement is widely used in the demolition \& fragmentation industry and will be the main focus of this report. The objective of this paper is to discuss the relationship between Sulfate-compounds on the expansion time and degree of expansion of Betonamit expansive cement. Based on literature [1], expansion time is directly proportional to sulfate content when mixed with Portland cement. Hence, as the sulfate content of the cement mixture increases, expansion time increases. However, in this research project the effect of Portland cement was removed to further examine the effect of sulfate on Betonamit only. This phenomenon was investigated using various concentrations of 4 different Sulfate-compounds. The results proved the possibility of decreasing the expansion time of Betonamit and, quite remarkably, a much greater degree of expansion was obtained.
\end{abstract}

Keywords: Expansive Cement, Betonamit, Sulphate-Compounds, Expansion Time, Degree of Expansion

\section{Introduction}

Nowadays, breakage of rock in underground mines is done by the use of explosives mainly dynamite. Such devices may be extremely dangerous to use in underground mines due to fly rock resulting from the blast as well as their sensitivity which may cause them to trigger off. In addition they tend to be quite harmful to the environment and the surrounding urban communities. Rock breakage using expansive cements doesn't require any special type of training of personnel. As a result it is desired to break rock using expansive cement which is much safer and more user friendly than dynamite. However, the only drawback of such a method is the amount of time it takes for the cement to expand and fully crack the surrounding rock. Currently, Betonamit (expansive cement) takes approximately 4-5 hours to expand completely and cause breakage. Such a time is economically unfeasible to be used in underground mines. It is desired to reduce that time to the matter of minutes which is the main challenge of this research project.

\section{Summary of Previous Work}

Similar work was done previously by Msunari and Mitri
[2] using expansive cement for the breakage of Norite rock. It was observed from the research and experiments conducted that expansive cements are indeed capable of breaking hard rock such as Norite. Breakage and cracking under loaded conditions occurs in the direction of loads in uniaxially loaded samples whereas radial cracking occurs in samples without loading. It was also deduced that expansive cements are capable of producing expansive stresses up to $120 \mathrm{MPa}$.

\section{Summary of Research Conducted}

In order for Betonamit to be economically feasible to be used in underground mines it's desired to reduce the rate of expansion to the course of minutes. From, [Cohen 1990], it was concluded that expansion rate is directly proportional to the amount of sulfate present in the cementitious system. Hence experiments with various sulfate compounds were conducted. These included Calcium Sulphate $\left(\mathrm{CaSO}_{4}\right)$, Barium Sulphate $\left(\mathrm{BaSO}_{4}\right)$, Potassium Sulphate $\left(\mathrm{K}_{2} \mathrm{SO}_{4}\right)$ and Copper Sulphate $\left(\mathrm{CuSO}_{4}\right)$.

The various $\mathrm{SO}_{4}$-Betonamit samples were prepared according to different weight percentages (wt\%). Those samples were then placed in cylindrical carton tubes and 
filled to approximately $3 / 4$ of the height. Since it approximately takes 4 hours for pure Betonamit to expand, all the cartons were left for a total of 6 hours. The degree of expansion and the rate at which the $\mathrm{SO}_{4}$-Betonamit system would take to fully expand was then measured.

\section{Literature Review}

\subsection{Expansion Mechanisms}

The expansion process of Betonamit isn't quite fully understood and as a result two schools of thought emerged to explain such a process [3]:

* Crystal Growth Theory (CGT)

* Swelling Theory (ST)

In CGT, ettringite growth from the surfaces of expansive particles is the main cause of expansion whereas in ST expansion is caused by water-adsorption and expansive characteristics of ettringite gel which forms by a through-solution mechanism [4]. However both schools overlap in the following points:

* Small crystals of ettringite are formed in the presence of lime, water and sulfates hence contributing to expansion

* Larger ettringite crystals are produced in the absence of lime, water and sulfates which do not contribute to expansion.

* Expansion and the size of ettringite crystals are affected by the presence of lime

\subsection{Effects of Sulfate and Expansive-Clinker Contents on Expansion Time}

The influence of particle size of sulfo-aluminate expansive clinkers and amount of sulfate on expansion time is important in selecting mixture proportions of reinforced expansive-cement. Expansion time of expansive-cement paste is dependent on physical and chemical characteristics of the individual ingredients and their respective proportions. It was previously deduced [5] that expansion time is directly proportional to the sulfate content of the cement system (assuming Portland cement is also added).

Note: Expansion rates based on sulfo-aluminate expansive clinkers were not investigated in this report due to their high cost.

\section{Experimental Procedure \& Results}

\subsection{Calcium Sulphate}

All samples were made of Betonamit expansive cement,
Calcium Sulfate $\left(\mathrm{CaSO}_{4}\right)$ and water. A total of 3 tests were conducted:

1) Effect of anhydrous $\mathrm{CaSO}_{4}$ on Betonamit;

2) Optimizing the amount of $\mathrm{CaSO}_{4}$;

3) Measuring the rate of expansion against that of pure Betonamit.

Test \#1: Procedure

In the 1 st test, 4 samples containing $0 \%, 15 \%, 30 \%$ and $50 \%$ of $\mathrm{CaSO}_{4}$ by wt\% were prepared as follows:

* The 1 st sample, $0 \%$, was simply prepared by measuring out $100 \mathrm{~g}$ of Betonamit using an electronic scale.

* The 2nd sample was prepared by measuring out $85 \mathrm{~g}$ of Betonamit and $15 \mathrm{~g}$ of $\mathrm{CaSO}_{4}$. The 3rd and 4th samples were prepared in a similar manner.

It should be noted that two replicated of each samples were done for repeatability and reliability. Moreover, water was added as a $20 \mathrm{wt} \%$ of the whole system i.e. $20 \mathrm{~g}$ in each case.

The samples were placed in cylindrical cartons of $5 \mathrm{~cm}$ diameter which have been slotted using an automatic cutter. Elastic bands were then placed around them. This allows one to measure the degree of expansion throughout the experimental process.

Test \#1: Results

As can be seen from both Table 1, Figure 1 and Figure 3 , it is evident that having a $15 \mathrm{wt} \%$ of $\mathrm{CaSO}_{4}$ in the system produces a greater degree of expansion as opposed to having only pure Betonamit $\left(0 \% \mathrm{CaSO}_{4}\right)$. Moreover, at $\mathrm{CaSO}_{4}$ concentrations higher than $15 \mathrm{wt} \%$ the degree of expansion is lower than pure Betonamit. Figure 2 below shows the samples at the beginning of the experiment.

\section{Test \#2: Procedure}

Four samples containing $0 \%, 5 \%, 10 \%$ and $15 \%$ of $\mathrm{CaSO}_{4}$ by wt\% were prepared in a similar manner as test \#1.

\section{Test \#2: Results}

From Table 2 and Figure 4, it could be seen that the greatest degree of expansion occurs in the range between $10 w t \%$ and $15 w t \%$. Below that threshold the degree of expansion becomes comparable with that of pure Betonamit.

\section{Test \#3: Procedure}

A sample of $15 \mathrm{wt} \% \mathrm{CaSO}_{4}$ was prepared alongside with a sample of pure Betonamit in a similar manner as test \#1 and test \#2. The degree of expansion every 30 minutes was measured using a ruler. This enables one to find after how long maximum expansion is obtained to deduce whether the addition of sulfate does indeed reduce expansion time or not.

From Table 3 it can be seen that maximum expansion 
Table 1. Slit diameter of the various $\mathrm{CaSO}_{4}$ samples.

\begin{tabular}{ccccc}
\hline & & \multicolumn{3}{c}{ Slit Width (cm) after } \\
\cline { 4 - 5 } $\begin{array}{c}\mathrm{CaSO}_{4} \\
\text { conc. wt\% }\end{array}$ & $\begin{array}{c}\text { Initial slit } \\
\text { diameter }(\mathrm{cm})\end{array}$ & $2 \mathrm{hr}$ & $4 \mathrm{hr}$ & $6 \mathrm{hr}$ \\
\hline 0 & 0 & 1.5 & 3 & 3.5 \\
0 & 0 & 0.3 & 3 & 3.5 \\
& & & & \\
15 & 0 & 0.1 & 1.5 & 4.7 \\
15 & 0 & 0.1 & 1.5 & 5 \\
& & & & \\
30 & 0 & 0.2 & 0.9 & 2.1 \\
30 & 0 & 0.2 & 0.5 & 1.2 \\
& & & & \\
50 & 0 & 0.5 & 1.6 & 2.1 \\
50 & 0 & 0.6 & 1.5 & 1.9 \\
\hline
\end{tabular}

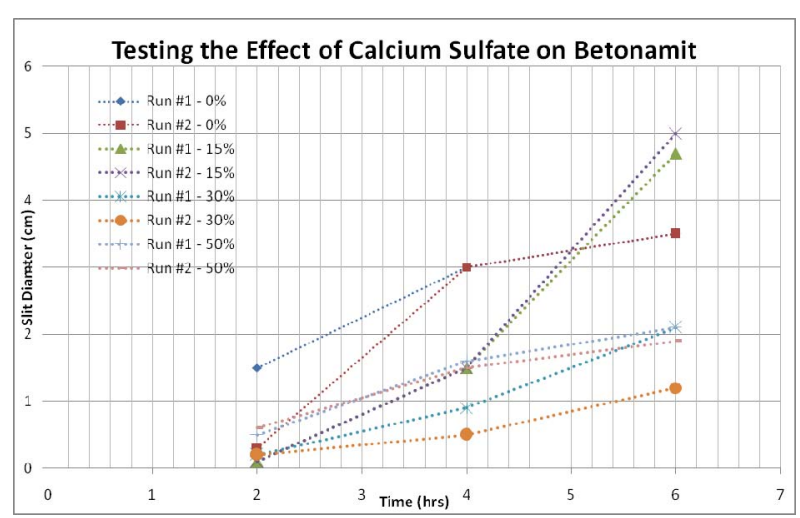

Figure 1. Testing the effect of $\mathrm{CaSO}_{4}$ on the expansive behavior Betonamit.

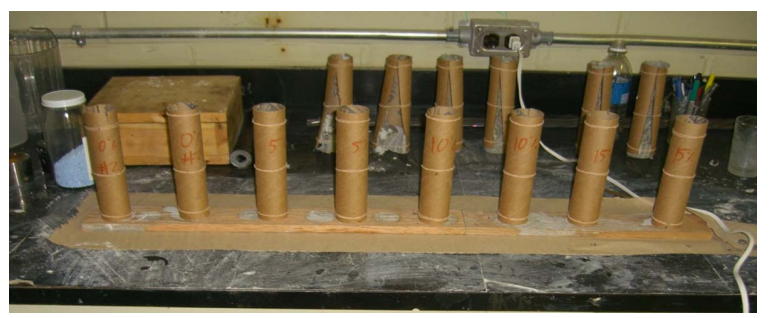

Figure 2. Samples from test $\# 1$ at $\mathbf{t}=0$.

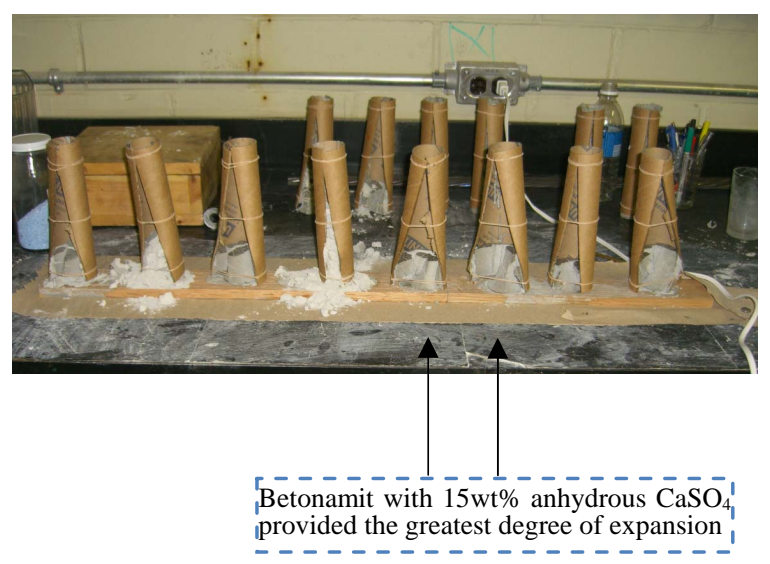

Figure 3. Samples from test \#1 at $\mathrm{t}=6 \mathrm{hrs}$.
Table 2. Optimizing the amount of $\mathrm{CaSO}_{4}$ added.

\begin{tabular}{ccccc}
\hline & & \multicolumn{3}{c}{ Slit Width (cm) after } \\
\cline { 3 - 5 } $\begin{array}{c}\mathrm{CaSO}_{4} \\
\text { conc. wt\% }\end{array}$ & $\begin{array}{c}\text { Initial slit } \\
\text { diameter }(\mathrm{cm})\end{array}$ & 2 & 4 & 6 \\
\hline 0 & 0 & 2.5 & 3.5 & 5 \\
0 & 0 & 1.5 & 3.5 & 4.5 \\
& & & & \\
5 & 0 & 1 & 2.5 & 6.5 \\
5 & 0 & 2 & 2.5 & 6 \\
10 & 0 & 0.5 & 1.5 & 7 \\
10 & 0 & 0.5 & 2 & 8 \\
15 & & & & \\
15 & 0 & 0.2 & 0.8 & 8 \\
\hline
\end{tabular}

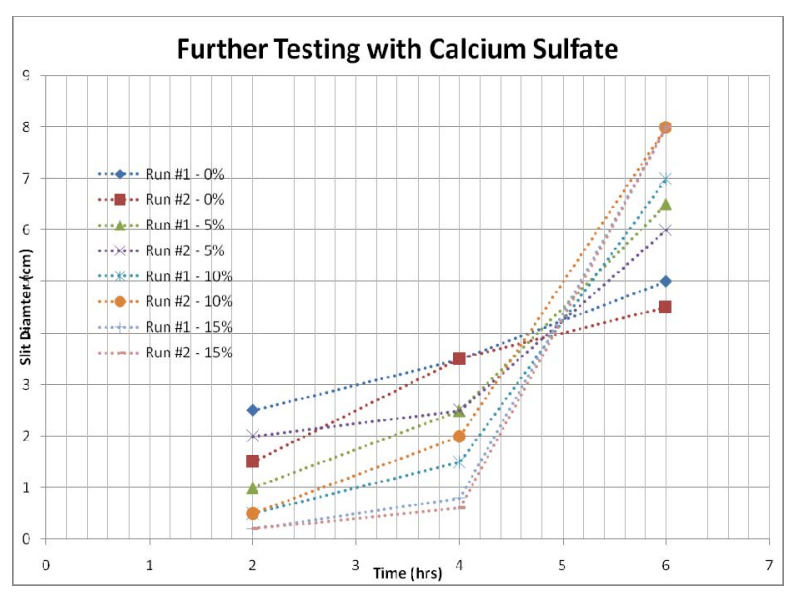

Figure 4. Further Testing with $\mathrm{CaSO}_{4}$.

for pure Betonamit is obtained after approximately 3 hrs 30 min whereas for Betonamit with $15 \mathrm{wt} \% \mathrm{CaSO}_{4}$ maximum expansion is obtained after approximately 5 hrs $30 \mathrm{~min}$.

\subsection{Potassium Sulphate $\left(\mathrm{K}_{2} \mathrm{SO}_{4}\right)$}

Similar to the previous experiment, all samples were made of Betonamit expansive cement, Potassium Sulfate $\left(\mathrm{K}_{2} \mathrm{SO}_{4}\right)$ and water. A total of 3 tests were conducted:

1) Effect of anhydrous $\mathrm{K}_{2} \mathrm{SO}_{4}$ on Betonamit;

2) Optimizing the amount of $\mathrm{K}_{2} \mathrm{SO}_{4}$;

3) Measuring the rate of expansion against that of pure Betonamit.

It should be noted that the same experimental procedure as that of Calcium Sulphate was used in all experiments with the remaining chemicals. 
Table 3. Expansion time of $15 w t \% \mathrm{CaSO}_{4}$.

\begin{tabular}{|c|c|c|c|c|c|c|c|c|c|c|c|c|c|}
\hline \multirow[b]{2}{*}{$\begin{array}{c}\mathrm{CaSO}_{4} \\
\text { conc. } \\
\text { wt } \%\end{array}$} & \multirow[b]{2}{*}{$\begin{array}{c}\text { Initial slit } \\
\text { diameter }(\mathbf{c m})\end{array}$} & \multicolumn{12}{|c|}{ Slit Width after } \\
\hline & & $30 \mathrm{~min}$ & $1 \mathrm{hr}$ & $\begin{array}{l}1 \mathrm{hr} \\
30 \mathrm{~min}\end{array}$ & 2 hrs & $\begin{array}{c}2 \mathrm{hr} \\
30 \mathrm{~min}\end{array}$ & $3 \mathrm{hrs}$ & $\begin{array}{c}3 \mathrm{hr} \\
30 \mathrm{~min}\end{array}$ & $4 \mathrm{hrs}$ & $\begin{array}{c}4 \mathrm{hr} \\
30 \mathrm{~min}\end{array}$ & $5 \mathrm{hr}$ & $\begin{array}{c}5 \mathrm{hr} \\
30 \mathrm{~min}\end{array}$ & $6 \mathrm{hr}$ \\
\hline $\mathbf{0}$ & 0 & 0.1 & 0.5 & 4 & 4.2 & 4.9 & 5.5 & 6.1 & 6.2 & 6.2 & 6.2 & 6.2 & 6.2 \\
\hline $\mathbf{0}$ & 0 & 0.1 & 0.3 & 1 & 3 & 6 & 6 & 6 & 6 & 6 & 6.1 & 6.1 & 6.1 \\
\hline 15 & 0 & 0.1 & 0.1 & 0.3 & 1 & 3 & 5.5 & 6.5 & 7.5 & 8 & 8.1 & 8.3 & 8.3 \\
\hline 15 & 0 & 0.1 & 0.1 & 0.2 & 1 & 2.6 & 5 & 6.4 & 7 & 7.5 & 8 & 8 & 8.3 \\
\hline
\end{tabular}

\section{Test \#1: Results}

As can be seen from Table 4, the degree of expansion after 6 hours was very small that almost no expansion occurred. As a result tests number 2 and 3 were not carried out as they would have proved to be futile.

\subsection{Copper Sulphate $\left(\mathrm{CuSO}_{4}\right)$}

All samples were made of Betonamit expansive cement, anhydrous Copper Sulfate $\left(\mathrm{CuSO}_{4}\right)$ and water. A total of 3 tests were conducted:

1) Effect of anhydrous $\mathrm{CuSO}_{4}$ on Betonamit;

2) Optimizing the amount of $\mathrm{CuSO}_{4}$;

3) Measuring the rate of expansion against that of pure Betonamit.

It should be noted that the same experimental procedure as that of Calcium Sulphate was used in all experiments with the remaining chemicals.

\section{Test \#1: Results}

As can be seen from Table 5 and Figure 5, the degree

Table 4. Slit diameter of the various $\mathrm{K}_{2} \mathrm{SO}_{4}$ samples.

\begin{tabular}{|c|c|c|c|c|}
\hline \multirow[b]{2}{*}{$\begin{array}{c}\mathrm{K}_{2} \mathrm{SO}_{4} \\
\text { conc. } w \mathrm{t} \%\end{array}$} & \multirow[b]{2}{*}{$\begin{array}{c}\text { Initial slit } \\
\text { diameter (cm) }\end{array}$} & \multicolumn{3}{|c|}{ Slit Width (cm) after } \\
\hline & & 2 hr & $4 \mathrm{hr}$ & $6 \mathrm{hr}$ \\
\hline $\mathbf{0}$ & 0 & 1.5 & 3 & 4 \\
\hline $\mathbf{0}$ & 0 & 0.3 & 3 & 3.5 \\
\hline 15 & 0 & 0.1 & 0.5 & 1 \\
\hline 15 & 0 & 0.1 & 0.4 & 1.2 \\
\hline 30 & 0 & 0.2 & 0.2 & 0.7 \\
\hline 30 & 0 & 0.2 & 0.2 & 0.5 \\
\hline 50 & 0 & 0.3 & 0.6 & 0.6 \\
\hline 50 & 0 & 0.3 & 0.7 & 0.7 \\
\hline
\end{tabular}

Table 5. Slit diameter of the various $\mathrm{CuSO}_{4}$ samples.

\begin{tabular}{|c|c|c|c|c|}
\hline \multirow[b]{2}{*}{$\begin{array}{c}\mathrm{CuSO}_{4} \\
\text { conc. wt\% } \\
\end{array}$} & \multirow[b]{2}{*}{$\begin{array}{c}\text { Initial slit } \\
\text { diameter }(\mathrm{cm})\end{array}$} & \multicolumn{3}{|c|}{ Slit Width (cm) after } \\
\hline & & $2 \mathrm{hr}$ & $4 \mathrm{hr}$ & $6 \mathrm{hr}$ \\
\hline 0 & 0 & 1.5 & 3 & 5 \\
\hline 0 & 0 & 0.5 & 3.5 & 4.5 \\
\hline 15 & 0 & 0.5 & 0.6 & 0.9 \\
\hline 15 & 0 & 0.4 & 0.6 & 0.8 \\
\hline 30 & 0 & 0.2 & 0.5 & 0.9 \\
\hline 30 & 0 & 0.1 & 0.4 & 1.0 \\
\hline 50 & 0 & \multicolumn{3}{|c|}{ No Expansion } \\
\hline 50 & 0 & \multicolumn{3}{|c|}{ No Expansion } \\
\hline
\end{tabular}

of expansion after 6 hours was very small with all $\mathrm{CuSO}_{4}$ percentages that almost no expansion occurred. Again similar to Potassium Sulphate, tests number 2 and 3 were not carried out.

\subsection{Barium Sulphate $\left(\mathrm{BaSO}_{4}\right)$}

The same experiments as mentioned before were con-

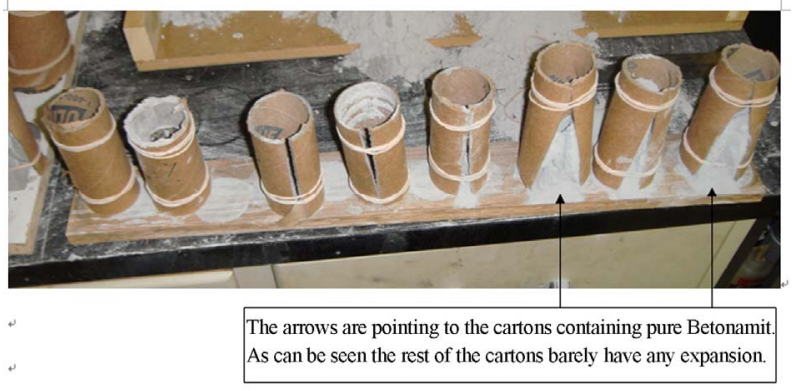

Figure 5. Slit diameters of the various $\mathrm{CuSO}_{4}$ samples. 
ducted using Barium Sulphate. However one slight modification was made and that was the addition of an extra $5 \%$ of Portland cement into the cement e.g. for a $100 \mathrm{~g}$ system 5 additional grams of Portland cement were added. The reason behind this is because upon curing, the system became powderous which would reduce the expansive strength of Betonamit.

As can be seen from Table 6 and Figure 6, it is evident that having a $30 \mathrm{wt} \%$ of $\mathrm{BaSO}_{4}$ in the system produces a greater degree of expansion as opposed to having only pure Betonamit $\left(0 \% \mathrm{BaSO}_{4}\right)$. Moreover, at $\mathrm{BaSO}_{4}$ concentrations higher than $30 \mathrm{wt} \%$ the degree of expansion is almost the same as pure Betonamit.

\section{Test \#2: Procedure}

Four samples containing 25\%, 35\% and $45 \%$ of $\mathrm{BaSO}_{4}$ by wt\% were prepared in a similar manner as test \#2 using Calcium Sulphate.

\section{Test \#2: Results}

From Table 7, it could be seen that the greatest degree of expansion occurs in the range between $25 \mathrm{wt} \%$ and 35wt\%. Figure 7 shows the carton with 35\% Barium Sulphate, which had the greatest expansion.

\section{Discussion}

From test \#1-CaSO 4 it was observed that the maximum degree of expansion was obtained in the range of $15 \mathrm{wt} \% \mathrm{CaSO}_{4}$. The suggested reason behind this is that at higher percentages of $\mathrm{CaSO}_{4}$ in the system ( $>15 \mathrm{wt} \%$ $\mathrm{CaSO}_{4}$ ) may hinder the effect of Betonamit itself and as a result not much expansion would occur. Similarly at very low percentages of $\mathrm{CaSO}_{4}$, the effect of $\mathrm{CaSO}_{4}$ on

Table 6. Slit diameter of the various $\mathrm{BaSO}_{4}$ samples.

\begin{tabular}{ccccc}
\hline & & \multicolumn{3}{c}{ Slit Width (cm) after } \\
\cline { 3 - 5 } $\begin{array}{c}\mathrm{BaSO}_{4} \\
\text { conc. wt\% }\end{array}$ & $\begin{array}{c}\text { Initial slit } \\
\text { diameter }(\mathrm{cm})\end{array}$ & $2 \mathrm{hr}$ & $4 \mathrm{hr}$ & $6 \mathrm{hr}$ \\
\hline 0 & 0 & 1.5 & 3.5 & 5 \\
0 & 0 & 2.5 & 4 & 5 \\
15 & 0 & 3 & 6.5 & 9.5 \\
15 & 0 & 2 & 5 & 9 \\
30 & 0 & 3.5 & 7 & 11 \\
30 & 0 & 4 & 8 & 12 \\
50 & 0 & 1.5 & 3.5 & 5 \\
50 & 0 & 2 & 3 & 4 \\
\hline
\end{tabular}

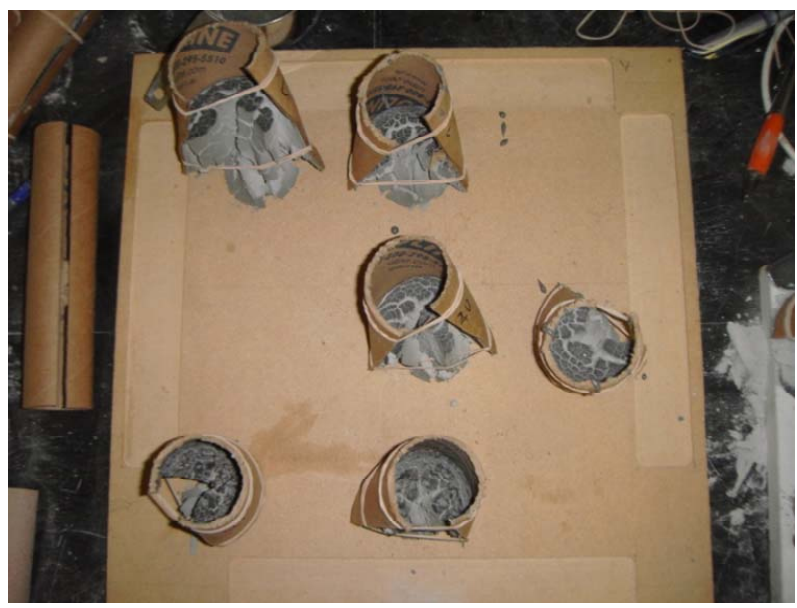

Figure 6. Slit diameters of the various $\mathrm{BaSO}_{4}$ samples.

Table 7. Optimizing the amount of $\mathrm{BaSO}_{4}$ added.

\begin{tabular}{ccccc}
\hline & & \multicolumn{3}{c}{ Slit Width (cm) after } \\
\cline { 3 - 5 } $\begin{array}{c}\mathrm{CaSO}_{4} \\
\text { conc. wt\% }\end{array}$ & $\begin{array}{c}\text { Initial slit } \\
\text { diameter (cm) }\end{array}$ & $2 \mathrm{hr}$ & $4 \mathrm{hr}$ & $6 \mathrm{hr}$ \\
\hline 25 & 0 & 3.5 & 7 & 8 \\
25 & 0 & 2.5 & 5 & 8 \\
35 & 0 & 4 & 6 & 12 \\
35 & 0 & 4.5 & 7 & 11 \\
45 & 0 & 3.5 & 5.5 & 10 \\
45 & 0 & 2.5 & 5 & 9 \\
\hline
\end{tabular}

the system may be negligible and hence the degree of expansion would be very close to that of pure Betonamit.

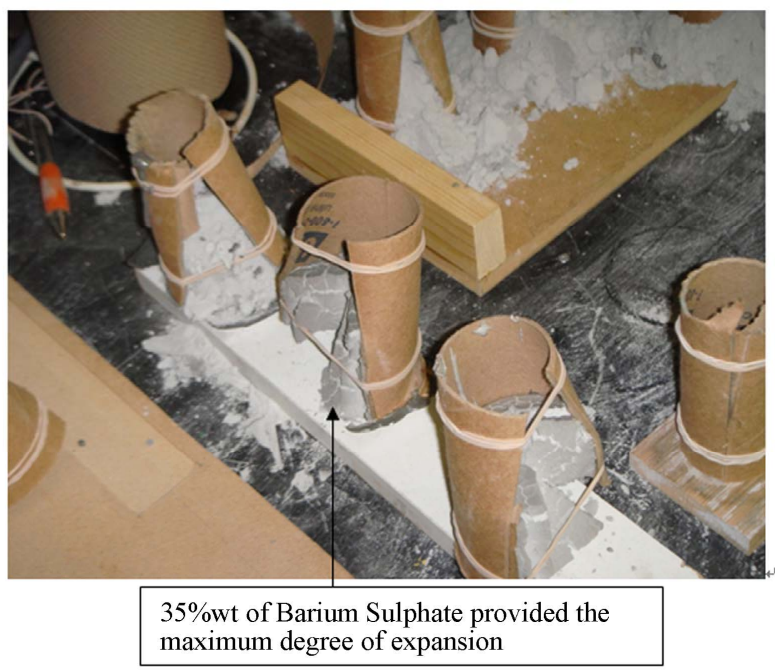

Figure 7. Cartons with Barium Sulphate. 
Further tests were then conducted to accurately find out at which $\mathrm{CaSO}_{4} \mathrm{wt} \%$ the maximum degree of expansion occurs. Hence from test \#2, it was deduced that the maximum degree of expansion occurred at $15 \mathrm{wt} \%$. Based on the results of test \#3, Betonamit reached its maximum expansion after approximately 3.5 hours whereas Betonamit with $15 \mathrm{wt} \% \mathrm{CaSO}_{4}$ took approximately 5.5hours. However the latter system had a greater degree of expansion after 3.5 hours which means that anhydrous Calcium Sulfate was effective in reducing the expansion time. Moreover it should be noted that there is a need to test $\mathrm{CaSO}_{4}$ with $5 \%$ Portland cement to study the effect of the post-curing process to check whether the matrix would become powderous or not.

Barium Sulphate produced the greatest expansion of all the 4 chemicals used. At approximately 35\%wt it provided an expansion of $\sim 12 \mathrm{~cm}$. Moreover, the rate of expansion was the highest where after 2 hours the system expanded up to $5 \mathrm{~cm}$. After 2 hours pure Betonamit expanded up to approximately $1.5 \mathrm{~cm}$ which proves that Barium Sulphate was indeed successful, like Calcium Sulphate, in reducing the expansion time.

From the experiment using Copper Sulphate, very minimal expansion occurred over the course of the 6hr period. Moreover, from the results of the $50 \%$ wt it was observed that no expansion occurred in the cartons. It is therefore safe to conclude that the $2 \mathrm{M}$ copper sulphate inhibited the formation of ettringite crystals which as a result inhibited the expansive process of Betonamit. Similarly the same conclusion could be drawn for the experiments using potassium sulphate. Hence, both of these chemical proved to be ineffective in reducing the expansion time of Betonamit.

\section{Conclusions}

In conclusion $\mathrm{BaSO}_{4}$ provided the largest degree of expansion and the highest rate of expansion as well followed by $\mathrm{CaSO}_{4}$. However, due to the high cost of Ba$\mathrm{SO} 4$ per kilogram basis it may be more favorable to use $\mathrm{CaSO}_{4}$ as the base chemical in future research when trying to optimize the expansion rate and degree of Betonamit.

Moreover, in order to ensure that the matrix doesn't become powderous after the curing process and to ensure that expansive stresses are maintained, a mixture of Calcium Sulphate Hemi-hydrate could be added to the mix- ture. When this compound, more commonly known as Gypsum, is heated to approximately $150^{\circ} \mathrm{C}$ it turns into an extremely strong material known as "Plaster of Paris". This compound, which is a type of building material, is extremely strong and "could" develop high expansive stresses while maintaining expansion [6].

\section{Future Work}

Since the expansion time wasn't successfully reduced to the course of minutes, this project has a vast area for research. Further testing with other sulfate compounds may give interesting insights on the expansion of Betonamit. Furthermore, the addition of a catalyst to speed up the curing \& expansive process of Betonamit may prove to be successful. However the greatest difficulty is finding such a catalyst which may be far more complex to be figured out in the period of months. In addition further experiments with the addition of Calcium Sulphate Hemihydrate should be conducted to explore the effect of this "strong" compound on the mixture matrix.

\section{References}

[1] M. D. Cohen and B. Mobasher, "Effects of Sulfate and Expansive Clinker Contents on Expansion Time of Expansive-Cement Paste," Cement and Concrete Research, Vol. 21, No. 1, 1991, pp. 147-157. doi:10.1016/0008-88 46(91)90041-F

[2] A. Msunari, "Laboratory Investigation into Rock Fracturing with Expansive Cement," Inderscience Enterprises Ltd., Vol. 1, No. 4, 2009, pp. 327-345.

[3] M. Collepardi, "Effects of Shrinkage Reducing Admixture in Shrinkage Compensating Concrete under NonWet Curing Conditions," Cement and Concrete Composites, Vol. 27, No. 6, 2005, pp. 704-708. doi:10.1016/j. cemconcomp.2004.09.020

[4] P. Mehta, "Mechanism of Expanson Associated with Ettringite Formation," Cement and Concrete Research, Vol. 3, No. 1, 1973, pp. 1-6. doi:10.1016/0008-8846(73) 90056-2

[5] M. Cohen, “Modelling of Expansive Cements," Cement and Concrete Research, Vol. 13, No. 4, 1983, pp. 519-528. doi:10.1016/0008-8846(83)90011-X

[6] N. S. Middendorf, "Progress in Crystal Growth and Characterization of Materials," Journal of Crsytal Growth, Vol. 53, No. 1, 2006. 